\title{
LESSONS FROM HISTORY
}

\section{"Preliminary Report on the Beneficial Effect of Chloromycetin in the Treatment of Typhoid Fever"- A Commentary}

\author{
Buddha Basnyat, MD, MSc, FACP
}

Typhoid fever, a human-specific systemic infection caused by the bacterium Salmonella enterica serotype Typhi, was an important cause of fever and death in the United States and Europe in the 19th century.,2 The provision of clean water and sanitary sewage systems has brought about a revolutionary change in the prevention of this illness. However, in many developing countries and especially in South Asia, this disease continues to wreak havoc. There are, according to best global estimates, at least 16 million new cases of typhoid fever each year, with 600000 resulting deaths. ${ }^{3}$ Almost all of these deaths occur in developing countries. At present, typhoid fever is clearly a neglected disease, and it has no profitability status for drug companies because it is a disease of the poor. However, in 1948, Ehrlich and associates in the research laboratories of Parke Davis prepared a crystalline antibiotic compound called chloromycetin. ${ }^{4}$ Chloromycetin, or chloramphenicol as it is often called, was very effective against rickettsial illnesses. In what turned out to be a landmark work in 1948, Theodore Woodward and colleagues from the United States and Malaysia published a paper in the Annals of Internal Medicine documenting the usefulness of chloromycetin in the treatment of typhoid fever. ${ }^{4}$ I have chosen this paper about the effective treatment of typhoid fever as a basis for commentary for several reasons.

The first reason for my choice of this paper is that the introduction of chloramphenicol in 1948 against typhoid fever (due in large part to this paper) transformed a severe, debilitating, and often fatal disease into a readily treatable condition. This probably engendered great enthusiasm in the treatment of infectious diseases, as this discovery continued to herald the dawning of a new era of effective antibiotics that was started by sulfonamides and penicillin. Subsequently, the successful treatment of tuberculosis with antibiotics was also carried out,

Direct correspondence to Nepal International Clinic, Lal Durbar, GPO BOX 3596, Kathamandu, Nepal (e-mail: rishisbas@wlink.com. $\mathrm{np})$. prompting many to believe wrongly that infectious diseases were beaten. It was an exciting time.

In addition, the article by Woodward et al qualifies as a landmark paper because it reported one of the first documented clinical trials using control patients (although not randomized), an idea that was introduced in the 1940 s by people like Sir Bradford Hill in Britain. ${ }^{5}$ There were 10 people in the treated group who were given chloramphenicol supplied by Parke Davis and 8 people in the control group. The findings of the usefulness of chloramphenicol against typhoid fever are strengthened in this paper because the control patients did poorly (prolonged period of fever and ultimately 1 death) compared to the treated group. Incidentally, the study would, in all likelihood, be stopped prematurely and both groups given chloramphenicol if conducted in the modern-day research environment.

Yet another important reason for my choice of this paper is that it was probably one of the first important, documented collaborative studies between major institutions in North America (Baltimore, MD) and a research institute in Asia. The study was carried out at the Institute of Medical Research, Kuala Lumpur, Malaya. While treating people for rickettsial illness near Kuala Lumpur, the authors of this paper encountered numerous cases of typhoid fever with febrile courses running from 6 to 7 weeks and decided to study chloramphenicol in the treatment of typhoid fever. It would most likely be fair to say that the research process was not delayed by the sort of necessary (but strict) institutional or ethical review board that regularly has to be dealt with today. In addition, there were probably no lengthy and elaborate consent forms needing to be filled out by patients.

This paper exemplifies an innocent era of cooperation between academia and industry that clearly produced some very useful results. There were no competing interests or conflicts of interest that needed to be declared, as few such concerns existed at that time. On reading this important paper for the first time, bearing in mind 
the unique demands on style and presentation that different editors make today on authors of original research, the writing to me felt as if the authors were describing an incident to a dear uncle, and clearly, it was very appealing.

There are many lessons for us within this classic publication. Although most of us may never have the opportunity to take part in such an important research finding as that documented in this paper, we can learn from the authors. Theodore Woodward and colleagues were clearly very innovative in their approach to problem solving. They not only collaborated effectively with different institutions (American and Malaysian), which were literally worlds apart, and with industry (Parke Davis in this case), but they also relied on an investigative approach, rarely used to date (control study), that led to groundbreaking findings and resulted in a reliable cure for a debilitating, often fatal illness. Without doubt, they kept clear, alert, and inquisitive minds - although chloramphenicol was used for rickettsial illnesses, no one, as far as we have been able to determine, used this drug for typhoid fever prior to the investigation launched by the authors.

These qualities would serve us all well, regardless of what our jobs are as health care professionals. In fact, with the increasing resistance of typhoid fever to the presently available antibiotics, ${ }^{6}$ we now face the real prospect that untreatable typhoid fever will reemerge and spell disaster for many parts of the developing world. Of course, travelers from the developed world must also be aware of this danger. People may need to come together again in an international effort to fight this neglected disease, just as Theodore Woodward and colleagues did so admirably more than half a century ago.

\section{References}

1. Osler W. The Principles and Practice of Medicine: Designed for the Use of Practitioners and Students of Medicine. 8th ed. New York, NY: D Appleton; 1912:46.

2. Parry CM, Hien TT, Dougan G, White NJ, Farrar JJ. Typhoid fever. N Engl J Med. 2002;347:1770-1782.

3. Ivanoff B. Typhoid fever: global situation and WHO recommendations. Southeast Asian J Trop Med Public Health. 1995;26(suppl 2):1-6.

4. Woodward TE, Smadel JE, Ley HL Jr, Green R, Mankikar DS. Preliminary report on the beneficial effect of chloromycetin in the treatment of typhoid fever. Ann Intern Med. 1948;29:131-134

5. Doll R, Hill AB. Sir Austin Bradford Hill and the progress of medical science. Br Med J. 1992;305:1521-1526.

6. Mirza SH, Beeching NJ, Hart CA. Multi-drug resistant typhoid: a global problem. J Med Microbiol. 1996;44: 317-319. 